Fifth International Conference on Sustainable Construction Materials and Technologies. http://www.claisse.info/Proceedings.htm

\title{
DURABILITY OF OILWELL CEMENT IN CO2-RICH ENVIRONMENTS
}

\author{
Mohammadreza Bagheri $^{1 \mathrm{a}}$, Seyed M. Shariatipour ${ }^{1 \mathrm{~b}}$, Eshmaiel Ganjian ${ }^{2}$ \\ ${ }^{1}$ Research Centre for Fluid and Complex Systems, Coventry University, Mile Lane, \\ CoventryCV1 2NL,UK, ${ }^{1 a}$ Email:<bagherim@coventry.ac.uk>, ${ }^{1 b}$ Email: < \\ seyed.shariatipour@coventry.ac.uk> \\ ${ }^{2}$ School of Energy, Construction and Environment, Built \& Natural Environment \\ Research Centre, Coventry University, Coventry CVI 5FB, UK, \\ Email:<e.ganjian@coventry.ac.uk>
}

\begin{abstract}
The anthropogenic emissions of carbon dioxide $\left(\mathrm{CO}_{2}\right)$ into the atmosphere is considered as one of the main reasons for global warming. The injection of $\mathrm{CO}_{2}$ into underground formations is an immediate to mid-term option to decrease the level of this gas in the atmosphere. Depleted oil and gas reservoirs are among the best candidates for the carbon capture and storage projects (CCS). The reason for this is based on the well-characterised structure of these type of underground formations through the different periods of their life. One of the most concerned problems associated with CCS projects is $\mathrm{CO}_{2}$ leakage through well cements. Oilwell cements exposed to $\mathrm{CO}_{2}$-bearing fluids undergo geomechanical and geochemical changes which may endanger their integrity. This paper aims at providing a framework to predict the lifespan of a cement exposed to $\mathrm{CO}_{2}$-bearing fluid using numerical modelling based on coupling geochemical and geomechanical processes. The main processes of the radial compaction and the radial cracking are investigated. It was shown that the radial cracking process leads to a definite lifespan of the cement matrix after being exposed to $\mathrm{CO}_{2}$-bearing fluids, while the radial compaction process can increase the durability of the cement matrix. Generally, this process becomes more effective with increasing the radial stress on the cement sheath from the surrounding rocks.
\end{abstract}

Keywords: Oilwell Cement; $\mathrm{CO}_{2}$ Storage; Cement Lifespan

\section{INTRODUCTION}

The released $\mathrm{CO}_{2}$ into the atmosphere due to human activities increased the average global temperature (Stocker et al., 2013). $\mathrm{CO}_{2}$ composes 9-26\% of greenhouse gases (GHG) emission (Kiehl and Trenberth, 1997). One of the plausible methods to decrease the level of the released $\mathrm{CO}_{2}$ into the atmosphere is capturing it from power 
plans and injection into depleted oil and gas reservoirs. One of the main concerned issues associated with CCS projects is the high number of wells which are drilled in potential oil and gas reservoirs. Near to 400,000 abandoned wells are located in the Alberta Basin in Canada, and more than one million in Texas, USA (Celia et al., 2006). Wells are direct connections between the depleted reservoirs and Earth's surface. Any defects within these wells potentially could convert into a $\mathrm{CO}_{2}$ leakage pathway which compromises the expense and time invested in CCS projects. Therefore, the characterisation of cement behaviour exposed to $\mathrm{CO}_{2}$-bearing fluids is crucial to determine the risk associated with CCS projects.

Once $\mathrm{CO}_{2}$ is injected into the depleted oil and gas reservoirs, it will begin moving beneath the caprock. However, it should be noted that the caprock itself will be affected by the presence of $\mathrm{CO}_{2}$-bearing fluids (Shariatipour, Pickup and Mackay, 2014, 2016; Onoja and Shariatipour, 2018). Based on this, both the cement sections within the caprock and reservoirs are vulnerable to face the $\mathrm{CO}_{2}$ plume. The injected $\mathrm{CO}_{2}$ dissolves in brine as a ubiquitous component within the pores of depleted oil and gas reservoir resulting in the formation of carbonic acid. Due to the large distance between injection wells and abandoned wells, the static condition assumed to dominate close to the abandoned wells (Rimmelé et al., 2008; Kutchko et al., 2009; Corvisier et al., 2010, 2013; Zhang et al., 2013).

$\mathrm{CO}_{2}$-bearing fluids react with the cement matrix and penetrate the cement matrix due to either of the diffusion or the advection phenomena (Druckenmiller and MarotoValer, 2005; Haghi et al., 2017). Usually, the diffusion is responsible for the permeation of $\mathrm{CO}_{2}$-bearing fluids into the cement matrix, while the advection almost acts on the cement surfaces in cracks, the cement-casing interface, and the cementrock interface (Huet, Prevost and Scherer, 2010; Deremble et al., 2011; Duguid, Radonjic and Scherer, 2011; Gherardi, Audigane and Gaucher, 2012; Bagheri, Shariatipour and Ganjian, 2018).

The permeation of $\mathrm{CO}_{2}$-bearing fluids accompanied by so-called carbonation process (Scherer and Huet, 2009; Huet, Tasoti and Khalfallah, 2011; Kari, Puttonen and Skantz, 2014; Ashraf, 2016; Šavija and Luković, 2016; Rezagholilou, Papadakis and Nikraz, 2017). This process results in the formation of calcium carbonate (hereafter referred to as calcite) within the cement pores which reduces the porosity and increases the cement stiffness (Kutchko et al., 2009; Mason et al., 2013; Nakano et al., 2014; Walsh et al., 2014; Ashraf, 2016; Hangx et al., 2016). The invasion of more quantity of $\mathrm{CO}_{2}$-bearing fluids into the cement matrix re-dissolve calcite and calcium silicate hydrate $(\mathrm{C}-\mathrm{S}-\mathrm{H})$ which leads to the stiffness reduction and an increase in the porosity (Kutchko et al., 2007; Huerta, Bryant and Conrad, 2008; Rimmelé et al., 2008; Fabbri et al., 2009; Duguid and Scherer, 2010; Lecampion et al., 2011; Brunet et al., 2013; Zhang et al., 2013; Walsh et al., 2014; Liaudat et al., 2018). This process is referred to as degradation occurring in the case of invading extra $\mathrm{CO}_{2}$-bearing fluids or decreasing $\mathrm{pH}$.

Because of the diffusion dominance over the geochemical reactions, in literature, a linear relationship between the penetration depth of the $\mathrm{CO}_{2}$-bearing fluids and the square root of time was suggested (Silva, Neves and De Brito, 2014; Ashraf, 2016; Phung et al., 2016; Šavija and Luković, 2016; Ta et al., 2016; Rezagholilou, Papadakis and Nikraz, 2017). Although, geochemical reactions affect the porosity, tortuosity, and 
connectivity, and subsequently the diffusion coefficient (Georget, Prévost and Huet, 2018). Moreover, geomechanical alterations within the cement matrix due to the overburden pressure, the radial pressure, and the fluid pressure also affect the cement matrix. Therefore, the cement alteration under high-pressure and high-temperature (HPHT) conditions found in underground formations seems complex. This paper aims at modelling the cement alteration in $\mathrm{CO}_{2}$-rich environments under HPHT conditions by coupling the geochemical and geomechanical processes.

\section{CHARACTERISATION OF THE GEOCHEMICAL CHANGES}

Prior to characterising the cement alteration, it should be noted that the cement matrix is a porous rock which is affected by the fluid pressure (sometimes referred to as pore pressure). Biot-Terzaghi effective stress was applied to account for the fluid pressure (Biot, 1955; Geertsma, 1957; Nur and Byerlee, 1971; Skempton, 1984; Nygård et al., 2006; Liu and Harpalani, 2014; Osipov, 2015). It was assumed that the cement matrix to be isotropic and behaves elastically before failing. Based on this, a general strain tensor was developed as follows:

$$
\varepsilon_{i j}=\frac{1}{2 \mu}\left(\sigma_{i j}-\frac{1}{3} \delta_{i j} \sigma_{k k}\right)+\frac{1}{9 K} \delta_{i j} \sigma_{k k}-\frac{1}{3 H} \delta_{i j} p,
$$

where $\varepsilon_{i j}$ is the strain tensor, and $i, j$ are the principle directions. $\delta_{i j}$ is Kroenecker's delta, $\sigma_{i j}$ is the Cauchy stress tensor, $p$ is the pore pressure, $\mu$ and $K$ are the shear modulus and the bulk modulus of rock without the pore pressure, respectively, and $\mathrm{H}$ is the effective modulus of the solid phase to account for the strain due to the pore pressure. $\sigma_{k k}$ can be calculated as following in cylinder coordinates:

$$
\sigma_{k k}=\sigma_{r}+\sigma_{\theta}+\sigma_{z}
$$

It can be deduced from Equation (1) that the fluid pressure only affects the normal stresses. To reduce the complexity of the equations governing the geomechanical changes, it is assumed that the displacements in the z-direction and r-direction are not a function of the radius and the height, respectively. Therefore, the following can be obtained:

$$
\begin{aligned}
& \frac{\partial u_{z}}{\partial r}=0 \\
& \frac{\partial u_{r}}{\partial z}=0 .
\end{aligned}
$$

and based on the symmetry for a cylindrical cement matrix, the following can be deduced:

$$
\begin{gathered}
u_{\theta}=0, \\
\frac{\partial u_{r}}{\partial \theta}=0, \\
\frac{\partial u_{z}}{\partial \theta}=0 .
\end{gathered}
$$

where $u_{r}, u_{\theta}$, and $u_{z}$ are displacements in the r-direction, $\theta$-direction and z-direction, respectively.

Therefore, one can compute the strain-displacement relations as following (Sadd, 2005): 


$$
\begin{gathered}
\varepsilon_{r}=\frac{\partial u_{r}}{\partial r}, \\
\varepsilon_{\theta}=\frac{u_{r}}{r}, \\
\varepsilon_{z}=\frac{\partial u_{z}}{\partial z} .
\end{gathered}
$$

It worth noting that the value of the $\frac{\partial u_{z}}{\partial z}$ is constant through any cross-section perpendicular to the z-direction, and hereafter will be referred to as $U_{z}$. Equilibrium equations can also be derived as following:

$$
\begin{gathered}
\frac{\partial \sigma_{\theta}}{\partial \theta}=0, \\
\frac{\partial \sigma_{r}}{\partial r}=\frac{\sigma_{\theta}-\sigma_{r}}{r}, \\
\frac{\partial \sigma_{z}}{\partial z}=0 .
\end{gathered}
$$

After some mathematical manipulations one can reach to the following:

$$
\begin{aligned}
& \sigma_{r}=(\lambda+2 \mu) \frac{\partial u_{r}}{\partial r}+\lambda\left(\frac{u_{r}}{r}+U_{z}\right)+p \frac{K}{H^{\prime}} \\
& \sigma_{\theta}=(\lambda+2 \mu) \frac{u_{r}}{r}+\lambda\left(\frac{\partial u_{r}}{\partial r}+U_{z}\right)+p \frac{K}{H^{\prime}} \\
& \sigma_{z}=(\lambda+2 \mu) U_{z}+\lambda\left(\frac{\partial u_{r}}{\partial r}+\frac{u_{r}}{r}\right)+p \frac{K}{H} .
\end{aligned}
$$

where $\lambda$ is Lame's constant which is defined in Equation (18).

With time, Young's modulus of the cement sheath around the steel casing changes radially due to the geochemical processes resulted from exposure to $\mathrm{CO}_{2}$-bearing fluids. Therefore, Young's modulus can be considered as a function of the radius.

$$
E=E(r)
$$

and,

$$
\begin{gathered}
\lambda(r)=K(r)-\frac{2}{3} \mu(r), \\
K(r)=\frac{E(r)}{3(1-2 \vartheta)} \\
\mu(r)=\frac{E(r)}{2(1+\vartheta)}
\end{gathered}
$$

Equations ( 18) to (20) shows that the $\lambda, K$, and $\mu$ are also a function of the radius. Equations ( 12) to (16) can be solved for a cylindrical cement matrix with an inside radius of $r_{\text {inside }}$ and initial outside radius of $R$ by considering the following boundary conditions:

$$
\begin{gathered}
\sigma_{r}=p_{0} \text { on, } r=R, \\
\frac{1}{\left(R_{\text {initial }}^{2}-r_{\text {inside }}^{2}\right)} \int_{r_{\text {inside }}}^{R} 2 r \sigma_{z} d r=\sigma_{c} \text { on }, z= \pm h, \\
u_{r}=0 \text { on, } r=r_{\text {inside }} .
\end{gathered}
$$

where $p_{0}$ is the confining radial pressure, $R_{\text {initial }}$ is the outside radius of the cylindrical cement matrix prior to the invasion of $\mathrm{CO}_{2}$-bearing fluids, $\sigma_{c}$ is the confining pressure 
due to the overburden column of the cement in the z-direction, $\pm h$ is the distance from the middle of the cement matrix in the z-direction, however, based on the assumptions in Equation ( 3 ) and (4), the value of the $\sigma_{c}$ is constant in any cross-section perpendicular to the $\mathrm{z}$-direction.

The Poisson's ratio is a function of the radius, although, an average value of 0.25 is considered for calculation in this paper assumed as a representative value in literature (Harsh, Shen and Darwin, 1990; Goodwin and Crook, 1992; Malhotra, 1996; Velez et al., 2001; Constantinides and Ulm, 2004; Chamrova, 2010; Wang and Subramaniam, 2011; Lavrov, Todorovic and Torsæter, 2016; Lavrov, 2018).

Young's modulus in every radial layer within a cylindrical cement matrix is a function of the porosity and its composition as following (Lafhaj et al., 2006; Li et al., 2006):

$$
E=E_{0}(1-\phi)^{n},
$$

In Equation ( 24) the parameter $E_{0}$ depends on the cement composition, which can be calculated when the porosity is zero.

The cement matrix can be considered as a composite material which its Young's modulus can be represented by the Voigt/Reuss model (Liu, Feng and Zhang, 2009; Zhu, Fan and Zhang, 2015). Based on the direct effect of materials which are formed or dissolved due to exposure to $\mathrm{CO}_{2}$-bearing fluids, the Voigt model is assumed as a representative method for the calculation of the cement Young's modulus. Therefore, Young's modulus of the cement matrix can be calculated as follows:

$$
E_{0}(r)=\sum_{i=1}^{N_{\text {comp }}} E_{i} f_{i}(r) .
$$

where, $E_{0}(r)$ and $E_{i}$ are the Young's modulus of the cement matrix and component $i$, respectively. $E_{0}(r)$ shows that the Young's modulus is a function of the radius, $r$, due to radial changes in the cement composition because of the reaction with the $\mathrm{CO}_{2}$ bearing fluids. $N_{\text {comp }}$ is the number of the composing components, $f_{i}(r)$ is the volume ratio of the component $i$ at radius $r$. It should be noted that,

$$
\sum_{i=1}^{N_{\text {comp }}} f_{i}(r)=1 .
$$

The system of Equations from ( 12) to (16) can be solved by considering the boundary conditions in Equations Error! Reference source not found. to ( 23) as follows:

$$
\begin{gathered}
\left(\lambda_{i}^{t}+2 \mu_{i}^{t}\right) \frac{u_{i+1}^{t}-u_{i}^{t}}{\Delta r}+\lambda_{i}^{t}\left(\frac{u_{i}^{t}}{r_{i}}+U_{z}\right)-\sigma_{r_{i}}^{t} \\
=-p \alpha_{i}^{t}, \quad i: 1, \ldots, N, \\
\left(\lambda_{i}^{t}+2 \mu_{i}^{t}\right) \frac{u_{i}^{t}}{r_{i}}+\lambda_{i}^{t}\left(\frac{u_{i+1}^{t}-u_{i}^{t}}{\Delta r}+U_{z}\right)-\sigma_{\theta_{i}}^{t} \\
=-p \alpha_{i}^{t}, \quad i: 1, \ldots, N, \\
\frac{\sigma_{r_{i+1}}-\sigma_{r_{i}}}{\Delta r}-\frac{\sigma_{\theta_{i}}^{t}-\sigma_{r_{i}}^{t}}{r_{i}}=0, \quad i: 1, \ldots, N-1, \\
2\left(\frac{p_{0}-\sigma_{N}}{\Delta r}\right)-\frac{\sigma_{\theta_{N}}^{t}-\sigma_{r_{N}}^{t}}{r_{N}}=0
\end{gathered}
$$




$$
\begin{gathered}
\sum_{i=1}^{N} 2 r_{i} \Delta r\left(\left(\lambda_{i}^{t}+2 \mu_{i}^{t}\right) U_{z}+\lambda_{i}^{t}\left(\frac{u_{i+1}^{t}-u_{i}^{t}}{\Delta r}+\frac{u_{i}^{t}}{r_{i}}\right)\right) \\
=R_{\text {initial }}^{2} \sigma_{c}-\sum_{i=1}^{N}\left(2 r_{i} \Delta r p \alpha_{i}^{t}\right), \\
u_{1}^{t}=0 .
\end{gathered}
$$

where, $u_{i}^{t}$ shows the radius displacement at a radius of $\left(r_{\text {inside }}+(i-1) \Delta r\right)$ and the time, $t, N$ is the number of the radial layers with thickness $\Delta r, \alpha_{i}^{t}$ can be calculated as following:

$$
\alpha_{i}^{t}=\frac{K_{i}^{t}}{H_{i}^{t}}
$$

\section{CALCULATION OF THE POROSITY}

The porosity of the cement matrix undergoes changes due to the geomechanical alteration within the physical properties of the cement matrix. The porous media are the environments which are available for reactions with $\mathrm{CO}_{2}$-bearing fluid. Therefore, the prediction of the cement porosity is of great importance. The porosity change due to geomechanical alterations can be calculated from the following equation (Harrold, 2001; Liu and Harpalani, 2014).

$$
\Delta \emptyset_{r_{\text {geomechanical }}}^{t}=-\left(\frac{1-\emptyset_{r_{\text {old }}}^{t}}{K_{r}^{t}}-\frac{1}{K_{s_{r}}^{t}}\right)\left(\sigma_{m_{r}}^{t}-\alpha_{i}^{t} p\right),
$$

where, $\Delta \emptyset_{r_{\text {geomechanical }}}^{t}$ is the porosity change at the radius of $r$ and the time, $t$, due to changes in the geomechanical properties of the cement matrix. $K_{r}^{t}$ and $K_{s_{r}}{ }^{t}$ are the bulk modulus of dry porous rock and grains at the time, $t$, and the radius, $r$, respectively. $\emptyset_{r_{\text {old }}}^{t}$ is the porosity of the cement matrix at the radius of $r$ and time, $t$, prior to geomechanical alterations. The mean stress, $\sigma_{m_{r}}^{t}$, at the time, $t$, and the radius, $r$ is calculated as following (Harrold, 2001):

$$
\sigma_{m_{r}}^{t}=\frac{1}{3}\left(\sigma_{r}^{t}+\sigma_{\theta}^{t}+\sigma_{z}^{t}\right)
$$

where $\sigma_{r}^{t}, \sigma_{\theta}^{t}$, and $\sigma_{z}^{t}$ are stresses in the r-direction, $\theta$-direction, and z-direction, respectively, at the time $t$, and the radius, $r$.

The cement matrix is also subjected to geochemical alterations (i.e., reactions of dissolution and precipitation). To simulate the geochemical alteration of the cement, CrunchFlow code is used which was developed by Steefel et al. (2015). This code solves the following essential equation simulating the energy, mass, and momentum conservation:

$$
\frac{\partial\left(\phi C_{j}\right)}{\partial t}=\nabla \cdot\left(D \nabla C_{j}\right)-\nabla\left(q C_{j}\right)+R_{j} \quad(j=1,2,3, \ldots n)
$$

where $\phi$ is porosity, $C_{j}$ is the concentration of the component $j\left(\mathrm{~mol} / \mathrm{m}^{3}\right), D$ is the combined diffusion-dispersion coefficient $\left(\mathrm{m}^{2} / \mathrm{s}\right), q$ is the Darcy velocity $\left(\mathrm{m}^{3} /\left(\mathrm{m}^{2} . \mathrm{s}\right)\right)$, and $R_{j}\left(\mathrm{~mol} /\left(\mathrm{m}^{2} . \mathrm{s}\right)\right)$ is total reaction rate obtained from summing up rates of precipitation and dissolution of involved minerals. 
The porosity at the time, $t$, and the radius, $r$, after performing the geochemical simulation in each step is calculated as following;

$$
\emptyset_{r_{\text {geochemical }}^{t}}^{t}=1-\sum_{i=1}^{N_{\text {mineral }}} V_{\text {mineral }_{i}}^{t}
$$

where, $N_{\text {mineral }}$ is the number of the involved minerals, $V_{\text {mineral }}^{t}$ is the volume percentage of mineral, $i$, at the time, $t . \emptyset_{r_{\text {geochemical }}}^{t}$ is the porosity at the radius of $r$ and the time, $t$, after the geochemical reactions. Therefore, the final porosity, in this paper, after considering the geomechanical and geochemical changes is calculated as following:

$$
\emptyset_{r}^{t}=\emptyset_{r_{\text {geochemical }}}^{t}+\Delta \emptyset_{r_{\text {geomechanical }}^{t}} .
$$

where $\emptyset_{r}^{t}$ is the porosity at the radius, $r$, and at the time, $t$.

\section{PREDICTION OF THE CEMENT FAILURE}

The Hoek-Brown failure envelope can predict the lifespan of the cement. A simplified version of this criterion was applied to calculate the lifespan of the cement as following:

$\left\{\begin{array}{c}\left(\sigma_{m_{r}}^{t}-p\right) \geq \sigma_{c i_{r}}^{t} \Rightarrow \text { the radial layer within the cement matrix fails } c \\ \left(\frac{2 p_{0}+\sigma_{c}}{3}-p\right) \geq \sigma_{c i}^{t} \Rightarrow \text { the whole cement matrix fails }\end{array}\right.$

where, $\sigma_{c i_{r}}^{t}$ is the compressive strength of the cement at the radius of $r$ and the time, $t, \sigma_{c i}^{t}$ is the averaged compressive strength of the whole cylindrical cement matrix.

\section{THE COMPOSITION OF CEMENT AND AQUEOUS PHASES}

Table 1 and Table 2 show the aqueous and cement composition within the cement matrix, respectively.

Table 1. The initial concentrations of composing phases of the brine (Brunet et al., 2013).

\begin{tabular}{|c|c|c|}
\hline $\begin{array}{c}\text { Aqueous phase } \\
\text { species (mol/L) }\end{array}$ & Cement Matrix & Brine \\
\hline $\mathbf{C O} \mathbf{2}(\mathbf{a q})$ & 0.00 & 0.50 \\
\hline $\mathbf{C a 2}{ }^{+}$ & 0.00 & 0.00 \\
\hline $\mathbf{C l -}$ & 0.17 & 0.17 \\
\hline $\mathbf{N a}^{+}$ & $\begin{array}{c}\text { As a conservative ion, } \\
\text { its concentration is } \\
\text { calculated based on } \\
\text { charge balance. }\end{array}$ & 0.17 \\
\hline $\mathbf{S i O}$ (aq) & 0.00 & 0.00 \\
\hline $\mathbf{p H}$ & 2.90 & 13.00 \\
\hline
\end{tabular}


Table 2. The initial volume factions of composing mineral phases of the cement matrix (Brunet et al., 2013).

\begin{tabular}{|c|c|c|}
\hline $\begin{array}{c}\text { Mineral phase composition } \\
\text { (Vol. \%) }\end{array}$ & $\begin{array}{c}\text { Cement } \\
\text { Matrix }\end{array}$ & Brine \\
\hline Portlandite & 13.00 & 0.00 \\
\hline Calcite & 0.00 & 0.00 \\
\hline C-S-H & 72.00 & 0.00 \\
\hline SiO2(am) & 0.00 & 0.00 \\
\hline Porosity (\%) & 15.00 & 1.00 \\
\hline
\end{tabular}

\section{RESULTS AND DISCUSSION}

In this work, it is assumed the compressional regime is dominating the surrounding rocks close to the cylindrical cement matrix. Under unconfined conditions cement is only under the vertical stress which leads to the formation of the parallel fractures with the direction of the maximum stress. At low confined conditions, shear-extensional fractures can be seen in the rock samples, with increasing the confining pressure, the cement behaviour changes from the brittle to ductile, and only a localized deformation is distinguishable at the shear surfaces (Nygård et al., 2006). The formation of the fractures or deformed shear surfaces has not yet been studied in the context of the cement matrix, to the author's knowledge. The shear or extensional fractures are highly conductive pathways for $\mathrm{CO}_{2}$ leakage, while localised deformation at the shear surface under high-confined pressures, could prevent further penetration of the $\mathrm{CO}_{2}$-bearing fluids to a high degree. Two mechanisms of the radial cracking and the radial compaction are considered to explain the behaviour of the radial layers in which the effective pressure outstrips the compressive strength.
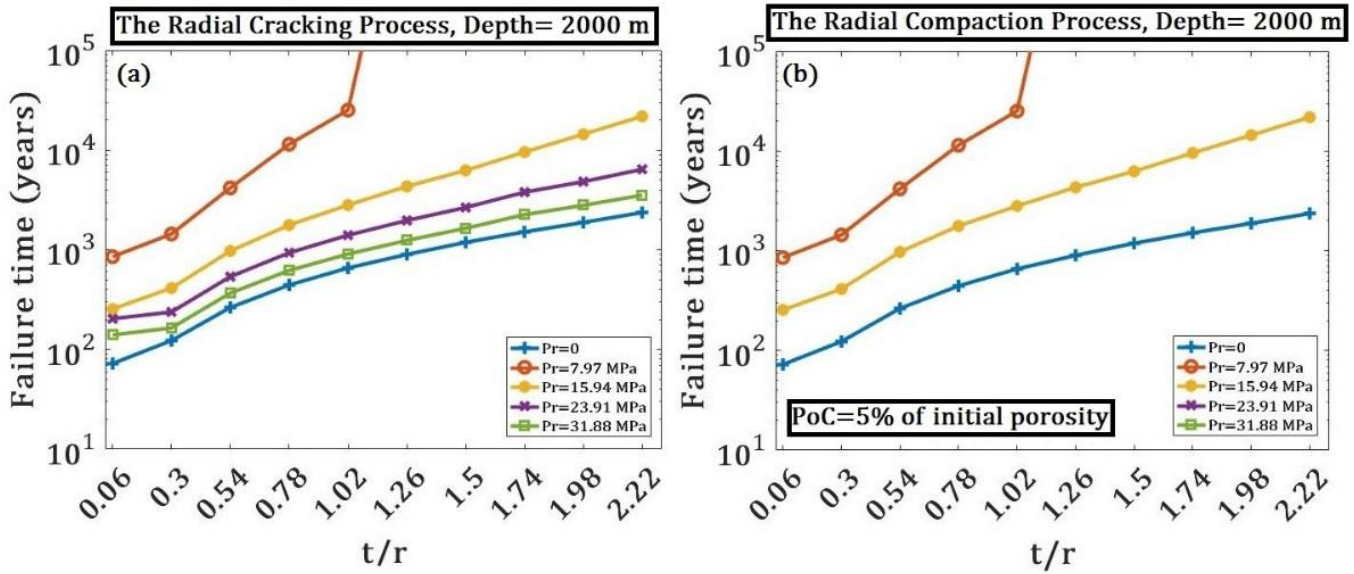

Figure 1. The prediction of the cement lifespan at depth of $2000 \mathrm{~m}$ vs. the ratio of the radial thicknesses of the cement over its inside radius ( $\mathrm{t} / \mathrm{r}$ ) at different values of radial pressure, (a) shows the effect of the radial cracking, and (b) shows the cement lifespan when the radial compaction is active, while the porosity of the compacted layers (PoC) decreases to $5 \%$ of its initial value. 
The invasion of $\mathrm{CO}_{2}$-bearing fluids results in the cement alteration, especially, within the outer layers. The impacted layers, in the case of brittle behaviour, are subject to the cracking both extensional or shear types. These cracks are highly conductive pathways to the interior parts of the cement. There is no difference considered between these two type of extensional and shear cracks. In fact, the performance of these two types of cracking mechanisms is similar. Figure 1 (a) shows that the cement lifespan increases 25 fold with increasing the $\mathrm{t} / \mathrm{r}$ from 0.06 to 2.22 . Indeed, with increasing the radial thickness of the cement matrix, the penetration depth of the cement becomes negligible in comparison with the cement radial thickness. It is also worth noting that reactions are not a function of the radial thickness. Thereby, increasing the cement lifespan with the increasing the $t / r$ is expected. Surprisingly, the maximum lifespan is expected for the radial pressure $(\operatorname{Pr})$ of $7.97 \mathrm{MPa}$, which at $\mathrm{t} / \mathrm{r}$ greater than 1.02 , the cement lifespan becomes unlimited. This value is $25 \%$ of the typical radial pressure which is expected at depth of $2000 \mathrm{~m}$. The minimum lifespan of the cement matrix occurs at Pr of zero. From 15.94 to $31.88 \mathrm{MPa}$, every $25 \%$ increase in the radial pressure, results in the reduction of the cement lifespan between 20 and $70 \%$ of its initial value.

Increasing the radial pressure to higher than 15.94 MPa results in an unlimited lifespan of the cement when the radial compaction is active (Figure 1 (b)). At the radial pressures equal or lower than $15.94 \mathrm{MPa}$, the maximum lifespan is expected for $\mathrm{Pr}$ of 7.97 MPa, and the minimum lifespan is for Pr of zero. The lifespan of the cement at radial pressures in the range of the zero to $50 \%$ of the typical radial pressure at the depth of $2000 \mathrm{~m}$ for the radial cracking process is comparable with radial compaction process. Generally, it can be concluded that increasing the radial pressure highly influences the compaction process and increases the cement lifespan, which is promising. The prediction of this behaviour is complex in the radial cracking process.

\section{CONCLUSION}

This paper provides a framework for predicting the cement lifespan at different depths by coupling the geochemical and geomechanical processes. The findings in this study can be outlined as below:

- At the depth of the $2000 \mathrm{~m}$, increasing the ratio of the radial thickness of the cement over the inside radius from 0.06 to 2.2 results in a 25 fold increase in the cement lifespan.

- When the radial cracking is active, the maximum lifespan of the cement is expected at the radial pressure of $25 \%$ of the typical radial pressure at the depth of $2000 \mathrm{~m}$.

- When the compaction process is active, generally, increasing the radial pressure prolongs the cement lifespan. However, under radial pressures greater than the $50 \%$ of the typical radial pressure at the depth of $2000 \mathrm{~m}$, the lifespan of the cement becomes unlimited.

- At PoC of 5\% and under radial pressures equal or lower than the 50\% of the typical radial pressure at the depth of $2000 \mathrm{~m}$, the lifespan of the cement matrix 
in the radial cracking and the radial compaction processes is comparable to each other.

This study considers the compressional regime near the well cement. Therefore, it is needed to investigate other probable conditions which may change the stress state within the cement matrix and the cement lifespan.

\section{AKNOWLEDGMENT}

We would like to express our appreciation to the Research Centre for Fluid and Complex Systems and the Centre for Built and Natural Environment at Coventry University for their support during developing this research work.

\section{REFERENCES}

Ashraf, W. (2016) 'Carbonation of cement-based materials: Challenges and opportunities', Construction and Building Materials. Elsevier Ltd, 120, pp. 558-570. doi: 10.1016/j.conbuildmat.2016.05.080.

Bagheri, M., Shariatipour, S. M. and Ganjian, E. (2018) 'A review of oil well cement alteration in $\mathrm{CO}_{2}$-rich environments', Construction and Building Materials. Elsevier Ltd, 186C, pp. 946-968. doi: 10.1016/j.conbuildmat.2018.07.250.

Biot, M. A. (1955) 'Theory of elasticity and consolidation for a porous anisotropic solid', Journal of Applied Physics, 26(2), pp. 182-185. doi: 10.1063/1.1721956.

Brunet, J. P. L. et al. (2013) 'Dynamic evolution of cement composition and transport properties under conditions relevant to geological carbon sequestration', Energy and Fuels, 27(8), pp. 4208-4220. doi: 10.1021/ef302023v.

Celia, M. A. et al. (2006) 'A risk assessment modeling tool to quantify leakage potential through wells in mature sedimentary basins', Proc. 8th Int. Conf. on Greenhouse Gas Control Technologies, Trondheim, Norway, (April 2015), pp. 1-6.

Chamrova, R. (2010) Modelling and Measurement of Elastic Properties of Hydrating Cement Paste.

Constantinides, G. and Ulm, F. J. (2004) 'The effect of two types of C-S-H on the elasticity of cement-based materials: Results from nanoindentation and micromechanical modeling', Cement and Concrete Research, 34(1), pp. 67-80. doi: 10.1016/S0008-8846(03)00230-8.

Corvisier, J. et al. (2010) 'Raman mapping and numerical simulation of calcium carbonates distribution in experimentally carbonated Portland-cement cores', European Journal of Mineralogy, 22(1), pp. 63-74. doi: 10.1127/09351221/2010/0022-1977. 
Corvisier, J. et al. (2013) 'A Numerical Model for $\mathrm{CO}_{2}$ Wells Ageing through Water/Supercritical $\mathrm{CO}_{2} /$ Cement Interactions', in Thermo-Hydromechanical and Chemical Coupling in Geomaterials and Applications. Hoboken, NJ, USA: John Wiley \& Sons, Inc., pp. 75-84. doi: 10.1002/9781118623565.ch5.

Deremble, L. et al. (2011) 'Stability of a leakage pathway in a cemented annulus', Energy Procedia. Elsevier, 4, pp. 5283-5290. doi: 10.1016/j.egypro.2011.02.508.

Druckenmiller, M. L. and Maroto-Valer, M. M. (2005) 'Carbon sequestration using brine of adjusted $\mathrm{pH}$ to form mineral carbonates', Fuel Processing Technology, 86(1415), pp. 1599-1614. doi: 10.1016/j.fuproc.2005.01.007.

Duguid, A., Radonjic, M. and Scherer, G. W. (2011) 'Degradation of cement at the reservoir/cement interface from exposure to carbonated brine', International Journal of Greenhouse Gas Control, 5(6), pp. 1413-1428. doi: 10.1016/j.ijggc.2011.06.007.

Duguid, A. and Scherer, G. W. (2010) 'Degradation of oilwell cement due to exposure to carbonated brine', International Journal of Greenhouse Gas Control. Elsevier Ltd, 4(3), pp. 546-560. doi: 10.1016/j.ijggc.2009.11.001.

Fabbri, A. et al. (2009) 'Effect of carbonation on the hydro-mechanical properties of Portland cements', Cement and Concrete Research. Elsevier Ltd, 39(12), pp. 11561163. doi: 10.1016/j.cemconres.2009.07.028.

Geertsma, J. (1957) 'The effect of fluid pressure decline on volumetric changes of porous rocks', Trans Am Inst Min Metall Pet Eng, 210, pp. 331-340.

Georget, F., Prévost, J. H. and Huet, B. (2018) 'Reactive transport modelling of cement paste leaching in brines', Cement and Concrete Research. Elsevier, 111(May 2017), pp. 183-196. doi: 10.1016/j.cemconres.2018.05.015.

Gherardi, F., Audigane, P. and Gaucher, E. C. (2012) 'Predicting long-term geochemical alteration of wellbore cement in a generic geological $\mathrm{CO}_{2}$ confinement site: Tackling a difficult reactive transport modeling challenge', Journal of Hydrology. Elsevier B.V., 420-421, pp. 340-359. doi: 10.1016/j.jhydrol.2011.12.026.

Goodwin, K. J. and Crook, R. J. (1992) 'Cement Sheath Stress Failure', SPE Drilling Engineering, 7(4), pp. 291-296. doi: 10.2118/20453-PA.

Haghi, R. K. et al. (2017) ' $\mathrm{pH}$ of $\mathrm{CO}_{2}$ saturated water and $\mathrm{CO}_{2}$ saturated brines: Experimental measurements and modelling', International Journal of Greenhouse Gas Control. Elsevier, 66(January), pp. 190-203. doi: 10.1016/j.ijggc.2017.10.001.

Hangx, S. J. T. et al. (2016) 'Defining the Brittle Failure Envelopes of Individual Reaction Zones Observed in $\mathrm{CO}_{2}$-Exposed Wellbore Cement', Environmental Science and Technology, 50(2), pp. 1031-1038. doi: 10.1021/acs.est.5b03097. 
Harrold, T. W. D. (2001) 'Porosity and effective stress relationships in mudrocks Porosity and effective stress relationships in By'.

Harsh, S., Shen, Z. and Darwin, D. (1990) 'Strain-rate sensitive behavior of cement paste and mortar in compression', ACI Materials Journal, 87(5), pp. 508-516. doi: $10.14359 / 1931$.

Huerta, N. J., Bryant, S. L. and Conrad, L. (2008) 'Cement Core Experiments With A Conductive Leakage Pathway, Under Confining Stress And Alteration Of Cement's Mechanical Properties Via A Reactive Fluid, As An Analog For $\mathrm{CO}_{2}$ Leakage Scenario', SPE/DOE Improved Oil Recovery Symposium, Tulsa, Oklahoma, 19-23 April, SPE-113375(Mueller 2004). doi: 10.2118/113375-MS.

Huet, B. M., Prevost, J. H. and Scherer, G. W. (2010) 'Quantitative reactive transport modeling of Portland cement in $\mathrm{CO}_{2}$-saturated water', International Journal of Greenhouse Gas Control. Elsevier Ltd, 4(3), pp. 561-574. doi: 10.1016/j.ijggc.2009.11.003.

Huet, B., Tasoti, V. and Khalfallah, I. (2011) 'A review of Portland cement carbonation mechanisms in $\mathrm{CO}_{2}$ rich environment', Energy Procedia. Elsevier, 4, pp. 5275-5282. doi: 10.1016/j.egypro.2011.02.507.

Kari, O. P., Puttonen, J. and Skantz, E. (2014) 'Reactive transport modelling of longterm carbonation', Cement and Concrete Composites. Elsevier Ltd, 52, pp. 42-53. doi: 10.1016/j.cemconcomp.2014.05.003.

Kiehl, J. T. and Trenberth, K. E. (1997) 'Earth's Annual Global Mean Energy Budget', Bulletin of the American Meteorological Society, 78(2), p. 5. doi: 10.1175/15200477(1997)078<0197:EAGMEB>2.0.CO;2.

Kutchko, B. G. et al. (2007) 'Degradation of Well Cement by $\mathrm{CO}_{2}$ under Geological Sequestration Conditions', Environ Sci Technol, 41(13), pp. 4787-4792. doi: 10.1021/es062828c.

Kutchko, B. G. et al. (2009) ' $\mathrm{CO}_{2}$ reaction with hydrated class $\mathrm{H}$ well cement under geologic sequestration conditions: Effects of flyash admixtures', Environmental Science and Technology, 43(10), pp. 3947-3952. doi: 10.1021/es803007e.

Lafhaj, Z. et al. (2006) 'Correlation between porosity, permeability and ultrasonic parameters of mortar with variable water/cement ratio and water content', Cement and Concrete Research, 36(4), pp. 625-633. doi: 10.1016/j.cemconres.2005.11.009.

Lavrov, A. (2018) 'Stiff cement, soft cement: Nonlinearity, arching effect, hysteresis, and irreversibility in $\mathrm{CO}_{2}$-well integrity and near-well geomechanics', International Journal of Greenhouse Gas Control, 70(June 2017), pp. 236-242. doi: 10.1016/j.ijggc.2017.11.012. 
Lavrov, A., Todorovic, J. and Torsæter, M. (2016) 'Impact of voids on mechanical stability of well cement', Energy Procedia. Elsevier B.V., 86(1876), pp. 401-410. doi: 10.1016/j.egypro.2016.01.041.

Lecampion, B. et al. (2011) 'Evolution of Portland Cement Mechanical Properties Exposed To $\mathrm{CO}_{2}$-Rich Fluids: Investigation At Different Scales', MPPS 2011, Symposium on Mechanics and Physics of Porous Solids: A tribute to Pr. Olivier Coussy, pp. 1-24.

Li, Y. X. et al. (2006) 'A study on the relationship between porosity of the cement paste with mineral additives and compressive strength of mortar based on this paste', Cement and Concrete Research, 36(9), pp. 1740-1743. doi: 10.1016/j.cemconres.2004.07.007.

Liaudat, J. et al. (2018) 'Modelling acid attack of oilwell cement exposed to carbonated brine', International Journal of Greenhouse Gas Control. Elsevier, 68(March 2017), pp. 191-202. doi: 10.1016/j.ijggc.2017.11.015.

Liu, B., Feng, X. and Zhang, S. M. (2009) 'The effective Young's modulus of composites beyond the Voigt estimation due to the Poisson effect', Composites Science and Technology. Elsevier Ltd, 69(13), pp. 2198-2204. doi: 10.1016/j.compscitech.2009.06.004.

Liu, S. and Harpalani, S. (2014) 'Determination of the effective stress law for deformation in coalbed methane reservoirs', Rock Mechanics and Rock Engineering, 47(5), pp. 1809-1820. doi: 10.1007/s00603-013-0492-6.

Malhotra, V. M. (1996) 'Concrete Admixtures Handbook', Concrete Admixtures Handbook, pp. 410-517. doi: 10.1016/B978-081551373-5.50011-8.

Mason, H. E. et al. (2013) 'Chemical and mechanical properties of wellbore cement altered by $\mathrm{CO}_{2}$-rich brine using a multianalytical approach', Environmental Science and Technology, 47(3), pp. 1745-1752. doi: 10.1021/es3039906.

Nakano, K. et al. (2014) 'Chemical interaction of well composite samples with supercritical $\mathrm{CO}_{2}$ along the cement - Sandstone interface', Energy Procedia. Elsevier B.V., 63, pp. 5754-5761. doi: 10.1016/j.egypro.2014.11.608.

Nur, A. and Byerlee, J. D. (1971) 'An exact effective stress law for elastic deformation of rock with fluids', Journal of Geophysical Research. Wiley-Blackwell, 76(26), pp. 6414-6419. doi: 10.1029/JB076i026p06414.

Nygård, R. et al. (2006) 'Brittle-ductile transition, shear failure and leakage in shales and mudrocks', Marine and Petroleum Geology, 23(2), pp. 201-212. doi: 10.1016/j.marpetgeo.2005.10.001. 
Onoja, M. U. and Shariatipour, S. M. (2018) 'The impact of gradational contact at the reservoir-seal interface on geological $\mathrm{CO}_{2}$ storage capacity and security', International Journal of Greenhouse Gas Control. Elsevier, 72(October 2017), pp. 1-13. doi: 10.1016/j.ijggc.2018.03.007.

Osipov, V. I. (2015) 'Physicochemical theory of effective stress in soils', Physicochemical Theory of Effective Stress in Soils, (Terzaghi), pp. 1-55. doi: 10.1007/978-3-319-20639-4.

Phung, Q. T. et al. (2016) 'Modelling the carbonation of cement pastes under a $\mathrm{CO}_{2}$ pressure gradient considering both diffusive and convective transport', Construction and Building Materials. Elsevier Ltd, 114, pp. 333-351. doi: 10.1016/j.conbuildmat.2016.03.191.

Rezagholilou, A., Papadakis, V. G. and Nikraz, H. (2017) 'Rate of carbonation in cement modified base course material', Construction and Building Materials. Elsevier Ltd, 150, pp. 646-652. doi: 10.1016/j.conbuildmat.2017.05.226.

Rimmelé, G. et al. (2008) 'Heterogeneous porosity distribution in Portland cement exposed to $\mathrm{CO}_{2}$-rich fluids', Cement and Concrete Research, 38(8-9), pp. 1038-1048. doi: 10.1016/j.cemconres.2008.03.022.

Sadd, M. H. (2005) Elasticity. Theory, Applications, and Numerics.

Šavija, B. and Luković, M. (2016) 'Carbonation of cement paste: Understanding, challenges, and opportunities', Construction and Building Materials, 117, pp. 285301. doi: 10.1016/j.conbuildmat.2016.04.138.

Scherer, G. W. and Huet, B. (2009) 'Carbonation of wellbore cement by $\mathrm{CO}_{2}$ diffusion from caprock', International Journal of Greenhouse Gas Control, 3(6), pp. 731-735. doi: 10.1016/j.ijggc.2009.08.002.

Shariatipour, S. M., Pickup, G. E. and Mackay, E. J. (2014) 'The Effect of Aquifer/Caprock Interface on Geological Storage of $\mathrm{CO}_{2}$ ', Energy Procedia. Elsevier, 63, pp. 5544-5555. doi: 10.1016/J.EGYPRO.2014.11.588.

Shariatipour, S. M., Pickup, G. E. and Mackay, E. J. (2016) 'Simulations of $\mathrm{CO}_{2}$ storage in aquifer models with top surface morphology and transition zones', International Journal of Greenhouse Gas Control. Elsevier, 54, pp. 117-128. doi: 10.1016/J.IJGGC.2016.06.016.

Silva, A., Neves, R. and De Brito, J. (2014) 'Statistical modelling of carbonation in reinforced concrete', Cement and Concrete Composites. Elsevier Ltd, 50, pp. 73-81. doi: 10.1016/j.cemconcomp.2013.12.001.

Skempton, A. W. (1984) 'Effective Stress in Soils, Concrete and Rocks', in SELECTED PAPERS ON SOIL MECHANICS. Thomas Telford Publishing, pp. 106- 
118. doi: 10.1680/sposm.02050.0014.

Steefel, C. I. et al. (2015) Reactive transport codes for subsurface environmental simulation, Computational Geosciences. doi: 10.1007/s10596-014-9443-x.

Stocker, T. F. et al. (2013) Climate Change 2013. doi: 10.1017/CBO9781107415324.Summary.

Ta, V.-L. et al. (2016) 'A new meta-model to calculate carbonation front depth within concrete structures', Construction and Building Materials. Elsevier, 129, pp. 172-181. doi: 10.1016/J.CONBUILDMAT.2016.10.103.

Velez, K. et al. (2001) 'Determination by nanoindentation of elastic modulus and hardness of pure constituents of Portland cement clinker', Cement and Concrete Research, 31(4), pp. 555-561. doi: 10.1016/S0008-8846(00)00505-6.

Walsh, S. D. C. et al. (2014) 'Experimental calibration of a numerical model describing the alteration of cement/caprock interfaces by carbonated brine', International Journal of Greenhouse Gas Control. Elsevier Ltd, 22, pp. 176-188. doi: 10.1016/j.ijggc.2014.01.004.

Wang, X. and Subramaniam, K. V. (2011) 'Ultrasonic monitoring of capillary porosity and elastic properties in hydrating cement paste', Cement and Concrete Composites. Elsevier, 33(3), pp. 389-401. doi: 10.1016/J.CEMCONCOMP.2010.11.001.

Zhang, L. et al. (2013) 'Reactive transport modeling of interactions between acid gas $\left(\mathrm{CO}_{2}+\mathrm{H}_{2} \mathrm{~S}\right)$ and pozzolan-amended wellbore cement under geologic carbon sequestration conditions', Energy and Fuels, 27(11), pp. 6921-6937. doi: 10.1021/ef401749x.

Zhu, H. X., Fan, T. X. and Zhang, D. (2015) 'Composite materials with enhanced dimensionless Young's modulus and desired Poisson's ratio', in Scientific Reports. Nature Publishing Group, pp. 1-8. doi: 10.1038/srep14103. 